\title{
Kinetics of HE4 and CA125 as prognosis biomarkers during neoadjuvant chemotherapy in advanced epithelial ovarian cancer
}

Jorge A. Alegría-Baños ${ }^{1,2^{*}}$ (D) José C. Jiménez-López ${ }^{3}$, Arely Vergara-Castañeda², David F. Cantú de León ${ }^{4}$, Alejandro Mohar-Betancourt ${ }^{4}$, Delia Pérez-Montiel ${ }^{4}$, Gisela Sánchez-Domínguez ${ }^{5}$, Mariana García-Villarejo ${ }^{6}$, César Olivares-Pérez ${ }^{6}$, Ángel Hernández-Constantino ${ }^{6}$, Acitlalin González-Santiago ${ }^{6}$, Miguel Clara-Altamirano ${ }^{7}$, Liz Arela-Quispe ${ }^{8}$ and Diddier Prada-Ortega ${ }^{4,9^{*}}$ (1)

\begin{abstract}
Background: Ovarian cancer (OC) is considered the most lethal gynecological cancer, of which more than 65\% cases are diagnosed in advanced stages, requiring platinum-based neoadjuvant chemotherapy (NACT).

Methods: A prospective-longitudinal study was conducted among women with advanced epithelial ovarian cancer (AEOC), III and IV stages, and treated with NACT, at the National Cancer Institute - Mexico, from July 2017 to July 2018. Serum samples were obtained for quantification of CA125 and HE4 using ELISA at the first and in each of the three NACT cycles. The therapeutic response was evaluated through standard tomography. We determined whether CA125 and HE4, alone or in combination, were associated with TR to NACT during follow up.
\end{abstract}

Results: 53 patients aged 38 to 79 years were included, $92.4 \%$ presented papillary serous subtype OC. Higher serum HE4 levels were observed in patients with non-tomographic response ( $6.89 \mathrm{vs} 5.19 \mathrm{pmol} / \mathrm{mL} ; p=0.031$ ), specially during the second $(p=0.039)$ and third cycle of NACT $(p=0.031)$. Multivariate-adjusted models showed an association between HE4 levels and TR, from the second treatment cycle $(p=0.042)$ to the third cycle $(p=0.033)$. Changes from baseline HE4 levels during the first cycle was negative associated with TR. No associations were found between CA125 and TR.

Conclusions: Serum HE4 levels were independently associated with TR among patients with AOEC treated with NACT, also a reduction between baseline HE4 and first chemotherapy levels was also independently associated with the TR. These findings might be relevant for predicting a lack of response to treatment.

Keywords: Biomarkers kinetic, HE4, CA125, Gynecological cancer, Ovarian cancer, Neoadjuvant chemotherapy

*Correspondence: a01684773@exatec.tec.mx; jorge_vikes@hotmai.com; dpradao@incan.edu.mx; dprada@cumc.columbia.edu

${ }^{1}$ Oncology Center, Médica Sur, Mexico City, Mexico

${ }^{4}$ Instituto Nacional de Cancerología, Colonia Seccion XVI, San Fernando

22, 14080 Tlalpan, Mexico City, Mexico

Full list of author information is available at the end of the article

\section{Introduction}

Ovarian cancer $(\mathrm{OC})$ is the second most common gynecological neoplasm, behind endometrial cancer, and is the most lethal gynecological cancer, being the eighth leading cause of cancer death in women [1]. Almost 80\% of cases are diagnosed as advanced stage disease. Current treatment for advanced epithelial ovarian cancer (AOEC) involves primary debulking surgery followed by a adjuvant chemotherapy regimen based on the combination of original author(s) and the source, provide a link to the Creative Commons licence, and indicate if changes were made. The images or other third party material in this article are included in the article's Creative Commons licence, unless indicated otherwise in a credit line to the material. If material is not included in the article's Creative Commons licence and your intended use is not permitted by statutory regulation or exceeds the permitted use, you will need to obtain permission directly from the copyright holder. To view a copy of this licence, visit http://creativecommons.org/licenses/by/4.0/. The Creative Commons Public Domain Dedication waiver (http://creativeco mmons.org/publicdomain/zero/1.0/) applies to the data made available in this article, unless otherwise stated in a credit line to the data. 
platinum and taxane, or the initial administration of neoadjuvant chemotherapy (NACT) followed by surgery [2]. The absence of residual disease in primary surgery is one of the most relevant prognostic factors for overall survival $[3,4]$. NACT and primary debulking surgery have the same efficacy when used at their maximal possibilities, but the toxicity profile is different. NACT is a treatment regimen that can be considered in selected patients [5-7], it does not negatively affect survival compared to primary debulking surgery plus postoperative chemotherapy and has even shown a significant reduction in perioperative complications and mortality $[8,9]$.

Tumor biomarkers are clinical or biological characteristics that are qualitatively or quantitatively modified because of a malignant neoplastic condition, being detectable in tissue or fluids [10] as prognosis tools, predictive markers for clinical efficacy, and therapeutic response assessment $[11,12]$. The tumor biomarker carbohydrate antigen 125 (CA125) is a high molecular weight glycoprotein $(>200 \mathrm{kD})$, expressed as a membrane-bund protein at the surface of the coelomic epithelium during embryonic development, and of cells that undergo metaplastic differentiation into a Müllerian-type epithelium [13]. Elevated serum CA125 levels can be detected under physiological circumstances (e.g., pregnancy), in benign gynecological and non-gynecological diseases, also in several malignant entities (e.g., ovarian, endometrial, breast, and colon cancers) $[13,14]$. With a cut-off serum level of $35 \mathrm{U} / \mathrm{mL}$, CA125 shows elevated values in $75 \%$ to $90 \%$ of patients with advanced ovarian cancer. It has a recognized role in the OC diagnosis, follow-up, treatment response assessment, and recurrence detection [15-17]. The CA125 has a sensitivity of $71 \%$ to $78 \%$ and a specificity of $75 \%$ to $94 \%$ for ovarian cancer diagnosis.

Some studies have analyzed the predictive value of CA125, based on the level reached at the end of NACT, in patients with ovarian epithelial cancer, yielding different cutoff points [18-21]. A reduction in CA125 to less than $65 \mathrm{IU} / \mathrm{mL}$, or a reduction greater than $50 \%$ from baseline, before neoadjuvant chemotherapy, was an independent prognostic factor for survival [22].

Human Epididymal Protein 4 (HE4) is a $13 \mathrm{kD}$ protein (20-25 kD in its mature glycosylated form); it belongs to the family of WAP-type four-disulfide core (WFDC), a group with potential trypsin inhibitory properties [2326]. It has been proposed as a proteinase inhibitor with utility in the pulmonary immune system and the sperm maturation process, and it is expressed at low concentrations in various healthy tissues, including the respiratory and reproductive epithelium [27]. HE4 is overexpressed in most subtypes of ovarian epithelial cancer [28] and some adenocarcinomas such as lung, endometrium and breast [29-32].

About its role in carcinogenesis, HE4 has been involved in cell cycle regulation and tumor cell proliferation, noting that the silencing of the HE4 gene results in cell cycle arrest in the G0/G1 phase and blocking the progression from the G1 phase to the synthesis or S phase [33, 34]. HE4 is overexpressed in ovarian carcinomas, with a cutoff serum level of $70 \mathrm{pmol} / \mathrm{L}$ with higher specificity (95\%) than CA125 [35]. HE4 can also be detected in urine with a specificity of $94.4 \%$ [36].

The exploration of the prognosis and predictive value of the combination of the biomarkers CA125 and HE4 in OC remains controversial [37-40]. In addition, several methodologies have been reported to assess tumor biomarker kinetics during OC treatment. Almufti et al., [41], classified the strategies and approaches to evaluate the prognostic and predictive utility of tumor biomarkers, based on the number of quantifications performed, which could be studies with a single measure or trials with two or more quantifications. over time, called kinetic studies. In the case of CA125 and HE4, their kinetics during NACT in OC has not been sufficiently investigated.

Finally, as a main objective, we set out to determine the kinetics of serological CA125 and HE4 during CO treatment and their associations with the tomographic response to platinum and taxane therapy in Mexican patients receiving neoadjuvant chemotherapy for advanced epithelial ovarian cancer.

\section{Materials and methods}

A longitudinal study was carried out, including women who attended the National Cancerology Institute-Mexico (NCI-Mx), from July 2017 to July 2018, age $>18$ years, with a diagnosis of epithelial ovarian cancer, with advanced disease, stages clinical III or IV from the International Federation of Gynecology and Obstetrics (FIGO) classification, candidates for treatment with neoadjuvant chemotherapy with carboplatin (area under the curve 5-6) and paclitaxel (175 $\mathrm{mg} / \mathrm{m} 2)$, every three weeks. Patients with a double primary tumor, mucinous histology, and those with previous cancer treatment (surgical or systemic) were excluded.

Serum samples were obtained for CA125 and HE4 quantification at the beginning of chemotherapy (baseline) and during every one of the three neoadjuvant treatment cycles. An evaluation of the therapeutic response was subsequently performed by the tomographic standard using the following criteria: "With a response", including complete and partial response,

or "No response", according to Response Evaluation Criteria In Solid Tumors (RECIST 1.1). 
The association between the CA125 and HE4 kinetics (absolute value and delta of change between the assessments) of biomarkers and the response tomographic was evaluated. We grouped tomographic response in " favorable response", which included full or partial response, and "no response", which included stable disease and disease progression. The serum HE4 and CA125 quantification were performed using the ARCHITECT HE4 assay by a method of Chemiluminescence Microparticle Immunoassay (CMIA).

To compare the values of the two biomarkers, normality was analyzed with histogram, Shapiro-Wilk, and Kolmogorov-Smirnov tests, observing the non-normality distribution of the data, thus a logarithmic transformation of the values was performed to be evaluated.
Descriptive and inferential tests, including correlations and a multivariate analysis adjusting by age, basal ECOG, smoking and clinical staging of the FIGO classification were performed.

\section{Results}

One hundred ninety-eight patients with ovarian cancer were initially included. From them, 116 patients (58.9\%) showed epithelial histological subtype and advanced stage of the disease. Only 53 patients (26.9\%) met the inclusion criteria for participation in the study. A previous surgical intervention (15.6\%) and a primary cytoreduction $(11.6 \%)$ were the most frequent causes of exclusion criteria (Fig. 1).

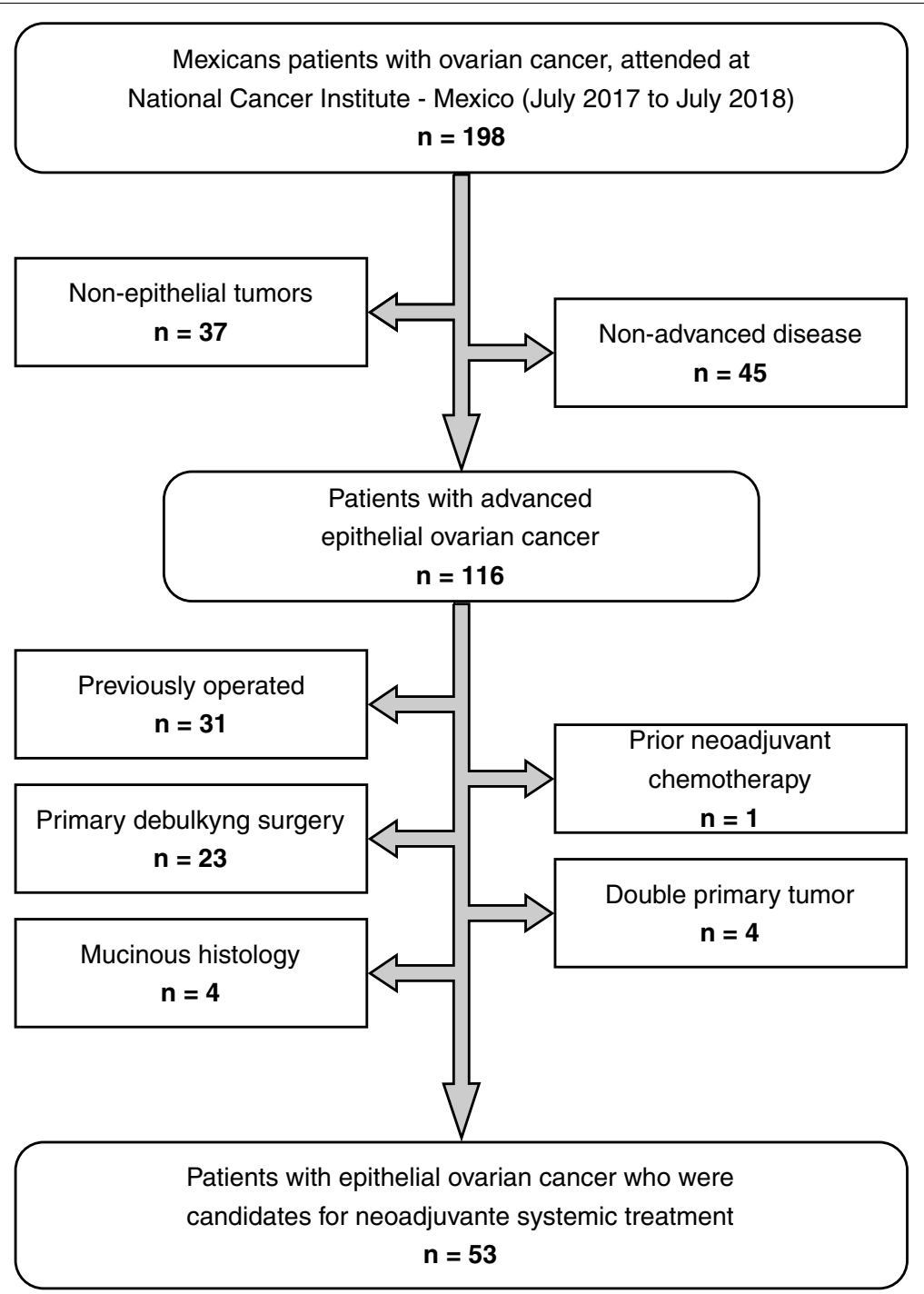

Fig. 1 Flowchart sample selection 
Of the 53 patients evaluated, we found a mean age of 57.8 years (Standard deviation [SD] 10.3 years). In this group, $43.4 \%$ was overweight, and $34.0 \%$ had high blood pressure. At diagnosis, the main symptoms were creased abdominal girth $75.5 \%$ and diffuse abdominal pain (66.6\%). The most frequent histopathological subtype was the papillary serous $(92.4 \%)$, and the majority $(52.8 \%)$ were in the clinical stage IVB.

The variable "tomographic response" was grouped into two categories: "with a response", which included full or partial response, those were 32 patients (60.4\%), and "no response", which included stable disease and disease progression, 21 patients (39.6\%).

The only variable that showed a statistically significant difference between both groups was the histological subtype. It was observed a significantly higher proportion $(p=0.044)$ of papillary serous cases (32 of 49 cases, $65.3 \%$ ) in the group with responses, vs 17 of 49 cases $(34.7 \%)$ in the group with no tomographic response, as well as the absence of endometrial subtypes and clear cells in the group with answer (Table 1 ).

The mean baseline HE4 was 2150.9 pmol / $\mathrm{mL}$ (range: 61.5-25,596.3) and that of CA125 was 5367.2 IU / mL (range: 28.2-36,262.4). The mean of both biomarkers decreased in each of the three cycles, with the greatest decline slope after the first cycle (Supplementary Table S1 and Fig. S1).

It was observed that patients with no tomographic response presented a higher level of HE4 [average of 6.19 (95\% CI, 4.92-6.84) pmol / $\mathrm{mL}]$ compared to the group that showed tomographic response [average of 5.89 (95\% CI, 5.65-6.78) pmol / $\mathrm{mL}$, with statistically significant difference $(p=0.031)$, this observation remains independently regardless the cycle where the sample was taken.

By analysing the association between basal HE4 serum levels and tomographic response, a higher concentration was found in patients with tomographic response group [7.13 (CI 95\%, 6.95-7.31) $\mathrm{pmol} / \mathrm{mL}$ vs 6.84 (CI 95\%, 6.64$7.04) \mathrm{pmol} / \mathrm{mL}$ ] with no statistically significant difference (Table 2). In each one of the treatment cycles, HE4 values were lower in tomographic response group with statistically significant difference for the second [5.32 (95\% CI, 5.17-5.47) pmol / $\mathrm{mL}$ versus 5.93 (95\% CI, 5.74-6.12) pmol / ml; $p=0.039$ ] and third cycle [4.91 (95\% CI, 4.795.03) $\mathrm{pmol} / \mathrm{mL}$ versus 5.56 (95\% CI, 5.44-5.68) pmol / $\mathrm{mL} ; p=0.031$ ] of treatment (Fig. 2).

By doing the multivariate analysis with an adjustment by age, basal ECOG, smoking and clinical staging of the FIGO classification, an association statistically significant was observed between HE4 levels and tomographic response, from the second cycle of treatment $(p=0.042)$,

Table 1 Clinicopathological characteristics of the patients according to tomographic response $(n=53)$

\begin{tabular}{|c|c|c|c|c|}
\hline Variable & Category & With response (\%) & Non response (\%) & $p^{\mathrm{a}}$ \\
\hline \multirow[t]{3}{*}{ Body mass index (WHO) } & Overweight & $12(37.5)$ & $11(52.4)$ & 0.934 \\
\hline & Normal & $13(40.6)$ & $6(28.6)$ & \\
\hline & Obese & $7(21.9)$ & $4(19.0)$ & \\
\hline \multirow[t]{2}{*}{ Diabetes mellitus } & Yes & $4(12.5)$ & $2(9.5)$ & 1.000 \\
\hline & No & $28(87.5)$ & $19(90.5)$ & \\
\hline \multirow[t]{2}{*}{ Systemic Arterial Hypertension } & Yes & $10(31.2)$ & $7(33.3)$ & 1.000 \\
\hline & No & $22(68.8)$ & $14(66.7)$ & \\
\hline \multirow[t]{2}{*}{ Smoking } & Yes & $6(18.7)$ & $2(9.5)$ & 0.335 \\
\hline & No & $26(81.3)$ & $19(90.5)$ & \\
\hline \multirow[t]{2}{*}{ ECOG } & $0-1$ & $29(90.6)$ & $20(95.2)$ & 0.065 \\
\hline & $\geq 2$ & $3(9.4)$ & $1(4.8)$ & \\
\hline \multirow[t]{3}{*}{ Histological subtype } & Papillary serous & $32(100)$ & $17(81.0)$ & 0.037 \\
\hline & Endometrioid & $0(0.0)$ & $3(14.2)$ & \\
\hline & Clear cell & $0(0.0)$ & $1(4.8)$ & \\
\hline \multirow[t]{5}{*}{ Clinical stage (FIGO) } & IVB & $18(56.3)$ & $10(47.6)$ & 0.914 \\
\hline & IVA & $7(21.9)$ & $9(42.9)$ & \\
\hline & $\| I I C$ & $5(15.6)$ & $2(9.5)$ & \\
\hline & $\| \mathrm{IIB}$ & $1(3.1)$ & $0(0.0)$ & \\
\hline & $\| \mathrm{A}$ & $1(3.1)$ & $0(0.0)$ & \\
\hline
\end{tabular}

Data is presented as $\mathrm{n}(\%)$

${ }^{\text {a }} \mathrm{X}^{2}$ tests

Those $p$ values with statistical significance (less than 0.05 ) are marked in bold 
Table 2 Association between HE4 levels ${ }^{a}$ and tomographic response $(n=53)$

\begin{tabular}{|c|c|c|c|c|c|c|}
\hline \multirow[b]{2}{*}{ HE4 } & \multicolumn{3}{|c|}{ Univariable } & \multicolumn{3}{|c|}{ Multivariable $^{b}$} \\
\hline & Estimated & $\mathrm{Cl} 95 \%$ & $p$ & Estimated & $\mathrm{Cl} 95 \%$ & $p$ \\
\hline Basal & -0244 & $-0.689,0.151$ & 0.357 & -0.262 & $-0.832,0.308$ & 0.367 \\
\hline To the first cycle & 0.444 & $-0-249,0.561$ & 0.119 & 0.524 & $-0.077,1.125$ & 0.088 \\
\hline To the second cycle & 0.676 & $0.061,1.081$ & 0.054 & 0.752 & $0.028,1.475$ & 0.044 \\
\hline To the third cycle & 0.766 & $0.175,1.181$ & 0.042 & 0.843 & $0.068,1.617$ & 0.033 \\
\hline All values & 0.241 & $0.012,0.352$ & 0.038 & 0.268 & $0.030,0.505$ & 0.027 \\
\hline
\end{tabular}

Cl confidence interval

a Transformed by decimal logarithm. Measurements of all cycles and basal values were included

b Adjusted for age at diagnosis, baseline ECOG, smoking the histological subtype and FIGO stage

Those $\mathrm{p}$ values with statistical significance (less than 0.05 ) are marked in bold

remaining until the third cycle $(p=0.033)$. By analyzing all values (basal and each cycle of chemotherapy), statistical significance was observed from univariate and multivariate analysis (Table 2).

Odds Ratio calculation was performed using the applicable variables, taking as response variable the result shown in the tomography after three cycles of chemotherapy. No significant value was found in the univariate analysis, and there was no multivariate model development (Supplementary Fig. S2).

The analysis of the values up to the sixth cycle, shows that the described behavior was also verified by comparing the difference values in serum levels with respect to the basal level. The data show that in patients with response this decrease is greater (Estimated Effect of -2.01 until the third cycle) compared with patients who showed no tomographic response (Estimated effect of
-1.19 until the third cycle). The correlation between the serum levels of the HE4 and CA125 biomarkers was explored, demonstrating collinearity, with similar trends at different times of treatment (Fig. 3).

The association between tomographic response and the difference (delta) between HE4 levels in different treatment cycles was analyzed, and we observed a statistically significant relationship between the difference in basal serum levels and those obtained after the first cycle of chemotherapy, both in the univariate analysis and in the age-adjusted multivariate model at diagnosis, basal ECOG, smoking and FIGO stage (Table 3). Thus, it was shown that a greater reduction between basal HE4 levels and those of the first cycle of chemotherapy was independently associated with the tomographic response. No statistically

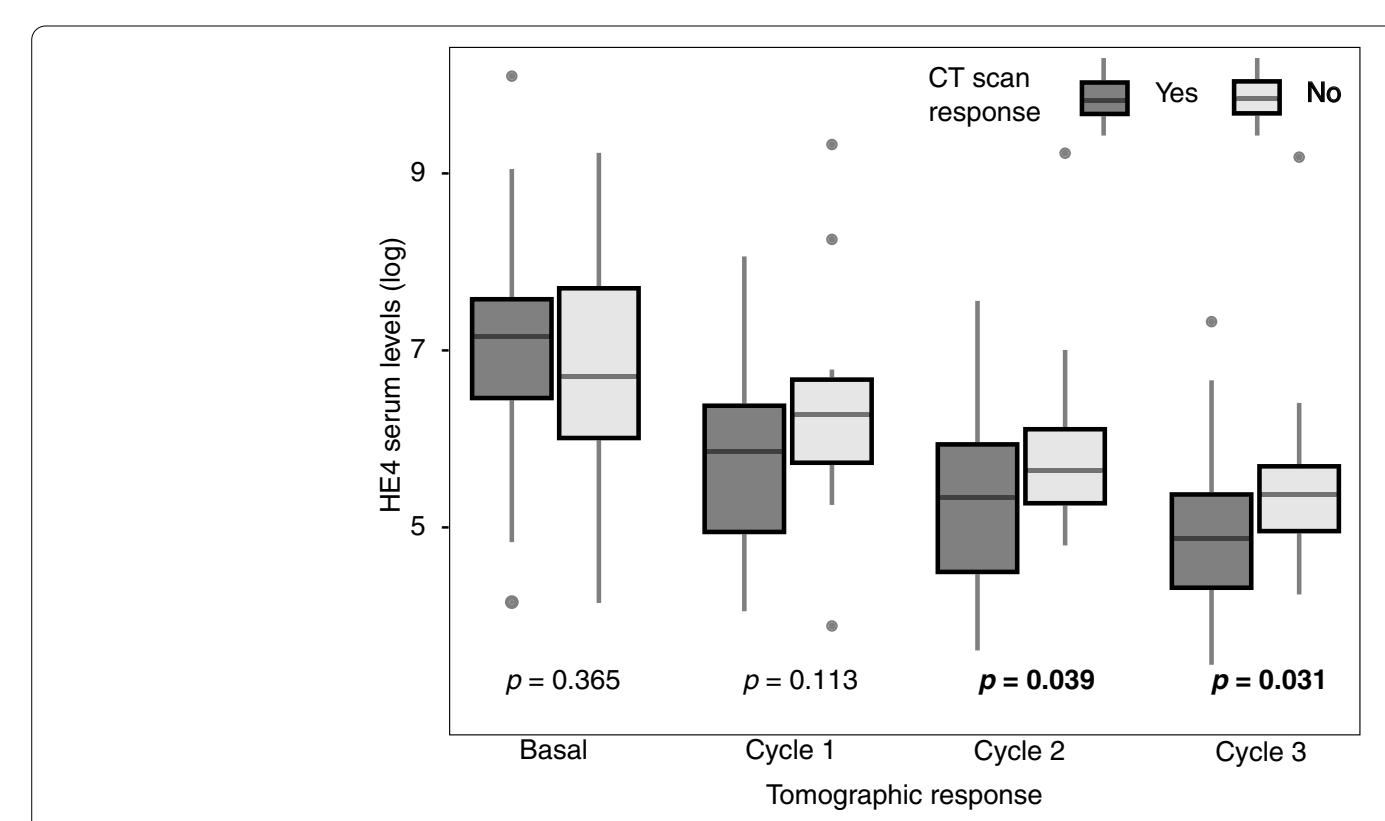

Fig. 2 HE4 levels according to tomographic responses and treatment cycle $(n=53)$. Comparisons between groups according tomographic response are reported using Two Sample T-Test (Welch's T-test). Those p values with statistical significance (less than 0.05) are marked in bold 

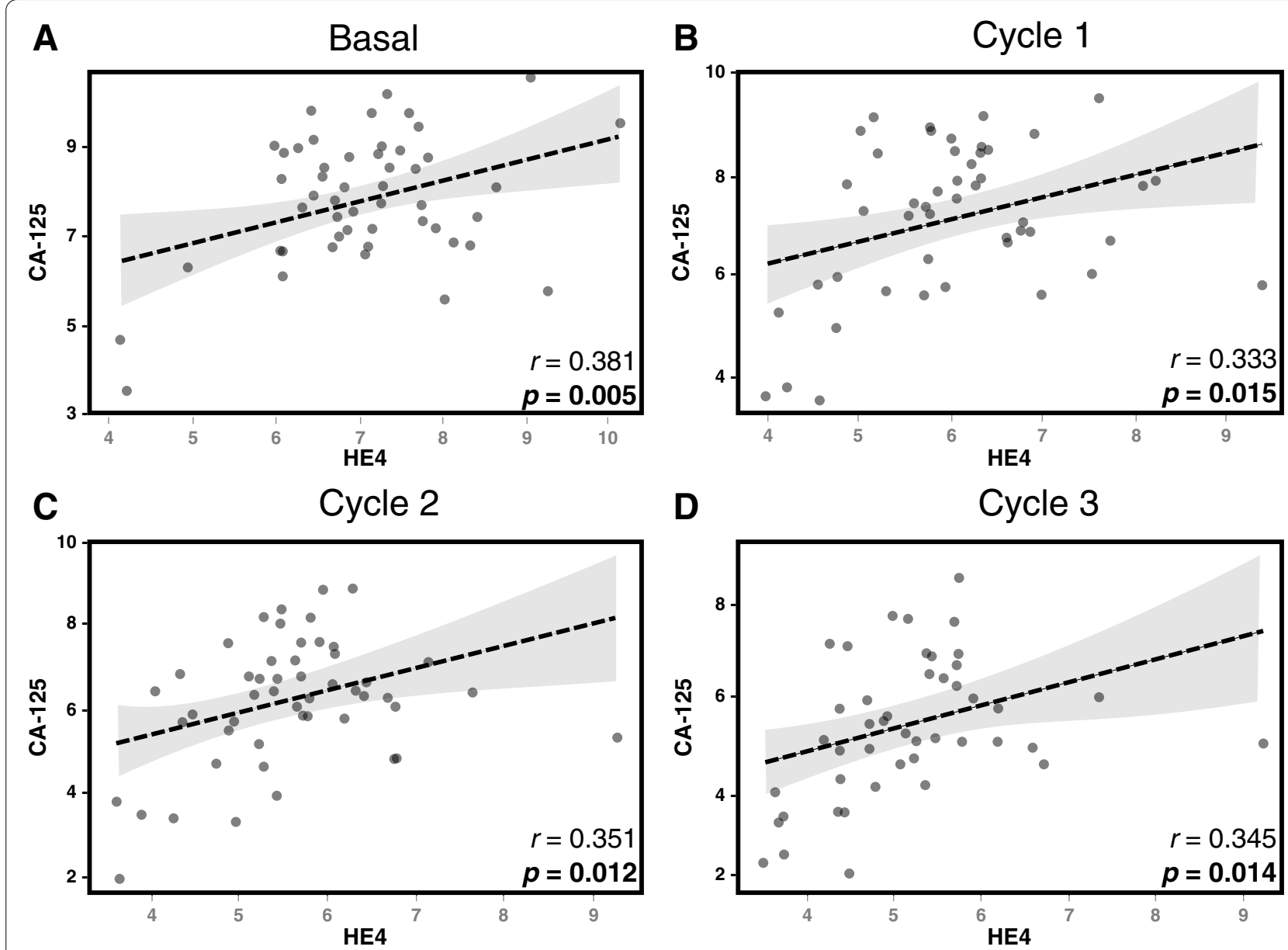

Fig. 3 Correlation between serological levels of HE4 and CA125 biomarkers during the different cycles $(n=53)$.Pearson's correlations shown in $\mathbf{A}$, B, $\mathbf{C}$ and $\mathbf{D}$ are statistically significative with a $p$-value $<0.05$

Table 3 Association between tomographic response and the difference (delta) between HE4alevels ( $n=53$ )

\begin{tabular}{|c|c|c|c|c|c|c|}
\hline \multirow[b]{2}{*}{ HE4 } & \multicolumn{3}{|c|}{ Univariate } & \multicolumn{3}{|c|}{ Multivariate $^{b}$} \\
\hline & Est & $\mathrm{Cl} 95 \%$ & $p$ & Est & $\mathrm{Cl} 95 \%$ & $p$ \\
\hline Between basal and first cycle & 0.182 & $0.033,0.330$ & 0.017 & 0.194 & $0.019,0.368$ & 0.030 \\
\hline Between basal and second cycle & 0.116 & $-0.013,0.245$ & 0.080 & 0.128 & $-0.013,0.269$ & 0.077 \\
\hline Between basal and third cycle & 0.090 & $0.060,0.240$ & 0.244 & 0.108 & $-0.058,0.274$ & 0.203 \\
\hline Between first and second cycle & 0.069 & $-0.125,0.263$ & 0.485 & 0.203 & $-0.092,0.498$ & 0.179 \\
\hline
\end{tabular}

Cl confidence interval

a Transformed by decimal logarithm

${ }^{\mathrm{b}}$ Adjusted for age at diagnosis, basal ECOG, smoking, histological subtype and FIGO stage

Those $\mathrm{p}$ values with statistical significance (less than 0.05 ) are marked in bold

significant relationship was observed with any other time comparison.

The most frequent adverse event associated with chemotherapy was neutropenia, present in 39 patients $(73.6 \%)$, being grade 3 or higher in 20 patients (37.6\%). The remaining toxicities were nausea in 24 patients $(45.3 \%)$, anemia in $22(41.5 \%)$, peripheral neuropathy in 16 (30.2), emesis in $12(22.6 \%)$, thrombocytopenia in 9 (17.0), diarrhea in 6 (11.3\%), and nephrotoxicity and hepatotoxicity in one patient (1.9\%), without showing a statistically significant distribution in relation to the tomographic response (Table 4). 
Table 4 Adverse events due to chemotherapy according to tomographic response to neoadjuvant chemotherapy $(n=53)$. Percentage values are calculated within groups

\begin{tabular}{|c|c|c|c|c|}
\hline \multicolumn{2}{|c|}{ Adverse event (CTCAE 5.0) } & \multirow{2}{*}{$\begin{array}{l}\text { With response } \\
\text { (\%) }\end{array}$} & \multirow{2}{*}{$\begin{array}{l}\text { Without } \\
\text { response } \\
(\%)\end{array}$} & \multirow{2}{*}{$\begin{array}{l}\text {-value } \\
0.582\end{array}$} \\
\hline Neutropenia & Grade 0 & & & \\
\hline & Grade 1 & $1(3.1)$ & $2(9.52)$ & \\
\hline & Grade 2 & $8(25.0)$ & $8(38.1)$ & \\
\hline & Grade 3 & $11(34.4)$ & $5(23.9)$ & \\
\hline & Grade 4 & $2(6.3)$ & $2(9.5)$ & \\
\hline \multirow[t]{4}{*}{ Anemia } & Grade 0 & $19(35.8)$ & $12(22.6)$ & 0.773 \\
\hline & Grade 1 & $5(9.4)$ & $2(3.8)$ & \\
\hline & Grade 2 & $7(13.2)$ & $5(9.4)$ & \\
\hline & Grade 3 & $1(1.9)$ & $2(3.8)$ & \\
\hline \multirow{4}{*}{$\begin{array}{l}\text { Thrombocyto- } \\
\text { penia }\end{array}$} & Grade 0 & $29(90.6)$ & $15(71.42)$ & 0.134 \\
\hline & Grade 1 & $2(6.2)$ & $1(4.8)$ & \\
\hline & Grade 2 & $0(0.0)$ & $3(14.3)$ & \\
\hline & Grade 3 & $1(3.1)$ & $2(9.5)$ & \\
\hline \multirow[t]{4}{*}{ Nausea } & Grade 0 & $19(57.6)$ & $11(52.4)$ & 0.953 \\
\hline & Grade 1 & $9(27.3)$ & $7(33.3)$ & \\
\hline & Grade 2 & $4(12.1)$ & $3(14.3)$ & \\
\hline & Grade 3 & $1(3.0)$ & $0(0.0)$ & \\
\hline \multirow[t]{3}{*}{ Emesis } & Grade 0 & $26(81.2)$ & $15(71.4)$ & 0.676 \\
\hline & Grade 1 & $4(12.5)$ & $5(23.8)$ & \\
\hline & Grade 2 & $2(6.3)$ & $1(4.8)$ & \\
\hline \multirow[t]{3}{*}{ Diarrhea } & Grade 0 & $27(84.4)$ & $20(95.2)$ & 0.781 \\
\hline & Grade 1 & $4(12.5)$ & $1(4.8)$ & \\
\hline & Grade 2 & $1(3.1)$ & $0(0.0)$ & \\
\hline \multirow[t]{2}{*}{ Renal toxicity } & Yes & $1(3.1)$ & $0(0.0)$ & 1 \\
\hline & No & 31 (96.9) & $21(100.0)$ & \\
\hline \multirow[t]{2}{*}{ Liver Toxicity } & Yes & $1(3.1)$ & $0(0.0)$ & 0.413 \\
\hline & No & 31 (96.9) & $21(100.0)$ & \\
\hline Peripheral & Grade 0 & $23(71.9)$ & $14(66.7)$ & 0.908 \\
\hline \multirow[t]{2}{*}{ Neuropathy } & Grade 1 & $5(15.6)$ & $3(14.3)$ & \\
\hline & Grade 2 & $4(12.5)$ & $4(19.0)$ & \\
\hline
\end{tabular}

${ }^{a}$ Fisher exact test; CTCAE 5.0: Common Terminology Criteria for Adverse Events version 5.0

\section{Discussion}

Ovarian cancer is the most lethal gynecological neoplasm in the world, due to its late diagnosis and nonspecific symptoms. Within the study, 198 patients with ovarian cancer were evaluated, of which 153 (77.2\%) presented advanced stage disease at the time of diagnosis (including epithelial and non-epithelial tumors), which is in line with what is reported in the international literature, where it has been indicated that more than $65 \%$ of patients are diagnosed in advanced stages [1]. The average age of presentation of the 53 patients included was 57.8 years $(\mathrm{SD} \pm 10.3$ years), lower than that reported globally, being 62 years $[1,42]$. This early presentation has been reported in other neoplastic diseases within the Mexican population, highlighting colorectal and prostate cancer.

The main documented comorbidities were overweight (45.2\%) and systemic arterial hypertension (43\%). The main symptoms were abdominal and nonspecific, in accordance with the literature [43], highlighting the increase in abdominal girth in 40 patients $(75.5 \%)$ and diffuse abdominal pain in 35 (66.6\%).

The only variable that showed statistically significant difference between both groups was the histological subtype, where patients with endometrioid and clear cells subtypes did not have favorable tomographic response with neoadjuvant treatment. Clear cell and mucinous subtypes in advanced disease are associated with a very poor prognosis and resistance to standard treatment [44, 45], however, this observation is limited in our study due to the small sample size (only one case with clear cell histology) and not including mucinous tumors because of their low production of HE4 biomarker.

Adverse events from chemotherapy occurred more frequently at the hematological and gastrointestinal levels, in accordance with the toxicity profile of the platinumtaxane combination reported in the literature. Some other frequent manifestations such as dysgeusia and headache were not reported during medical visits, in up to $11.8 \%$ and $7.1 \%$ of cases, respectively.

Regarding the biomarker HE4, it has demonstrated protease activity and participation in cell signalling, acting on processes of adhesion, migration, and promotion of tumour growth $[46,47]$. In addition to its standard use, approved for the differential diagnosis of malignant adnexal tumors (Risk of Ovarian Malignancy Algorithm), there are assays that explore the value of HE4 as a prognostic marker [48], a predictor of optimal cytoreduction [49], and a potential tool for early diagnosis of recurrence, even better than CA125 [50, 51].

Most of the reports published to date are retrospective. Studies that relate the role of HE4 to the response to chemotherapy often address the adjuvant setting, following primary cytoreduction. In addition, the authors have used various trials (ARCHITECT by Abott ${ }^{\circledR}$, ELECSYS by Roche $^{\circledR}$, or EIA by Fujirebio ${ }^{\circledR}$ ) and various statistical methods and approaches for data analysis (percentage decrease, low area to Curve, negativization, etc.), which increase heterogeneity and limit the comparison of results.

The pioneering study, which serves to contrast the results of the work carried out in this investigation, was published by Vallius and cols. [52], where 25 patients with advanced epithelial ovarian cancer, treated with 
neoadjuvant chemotherapy, were evaluated, quantifying the CA125 and HE4 biomarkers in a basal manner and on a later occasion, after completion of adjuvant chemotherapy, prior to interval cytoreduction. The percentage changes of the biomarkers were compared according to the tomographic response and the surgical outcome, concluding that neither CA125 nor HE4 changes were correlated with the tomographic response, observing a clear reduction in serum levels of both biomarkers in all groups, regardless of the radiological response. In fact, patients with disease progression had an average decrease in CA125 levels of around 83\%. This was surprising, since in the pilot study with 11 patients previously conducted, a relationship was observed between changes in serum concentration of biomarkers and the tomographic response.

Despite this finding, the report by Vallius and cols. described a favorable relationship between HE4 decline $(>80 \%)$ and prognosis in terms of overall survival, with a median of 3.38 versus 1.60 years $(p=0.01)$. This put into question the discordance between survival results and radiological therapeutic response. The authors argued that tomographic guidelines may be a limitation in the optimal assessment of the response to chemotherapy, suggesting to study, the possibility of using functional imaging as PET-CT to optimize the assessment. In addition to the small number of patients, a limitation of the study by Vallius and cols. was to have only two measurements for each patient.

Chudecka and cols. [53], published a study involving 90 patients with ovarian cancer, 42 of whom were treated with neoadjuvant chemotherapy, with HE4 and CA125 measurements taken at diagnosis, after chemotherapy, and before interval cytoreductive surgery, although in the final analysis, the authors only considered the third cycle of chemotherapy.

Preoperative HE4 levels were a predictor of platinum sensitivity $(p$-value $=0.035)$ and progression-free survival $(p$-value $=0.0492)$ when normalized or reduced by $50 \%$, but, unlike the reports of Vallius and cols. [52], in multivariate analysis, normalized HE4 levels after chemotherapy $(\mathrm{HR}=0.08, p$-value $=0.0003)$ or with $50 \%$ reduction before interval debulking $(\mathrm{HR}=0.39, p$-value $=0.0496)$, correlated with improvement in 2 years overall survival.

The present study is original in its design and tries to optimize the limitations of the reported studies previously. It only includes patients with advanced epithelial ovarian cancer treated with neoadjuvant chemotherapy, excluding the group of patients treated with primary cytoreductive therapy and those who have undergone incomplete surgery (oophorectomy, lumpectomy) prior to the start of systemic treatment, due to the alteration that this procedure conditions in the serum level of the biomarkers. In addition, baseline quantifications have been performed and in each cycle of systemic treatment, including all measurements within the final statistical analysis.

Unlike what was reported by Vallius and cols. [52], in this study a statistically significant association was observed between HE4 changes and the tomographic response in patients with epithelial ovarian cancer treated with NACT. These observations highlight the need to increase the sample size (11 and 25 patients, respectively, in the pilot and the trial by Vallius and cols.; 42 patients in the study by Chudecka and cols., standardize the number and timing of the quantifications, as well as the inclusion criteria, homogenizing the type of chemotherapy to be studied (neoadjuvant versus adjuvant) and analyzing both biomarkers to determine the collinearity of the results.

The main findings of our study are that HE4 levels, especially during the second and third cycle, are independently associated with the tomographic response in patients with advanced epithelial ovarian cancer treated with neoadjuvant chemotherapy. Also, a greater reduction between the basal HE4 levels and those of the first cycle of chemotherapy was independently associated with the tomographic response, which is relevant to predict the group of patients who will not respond to treatment. The analysis of the delta was included due to its potential clinical relevance since the decision of continuing or not with more chemotherapy cycles could be made after the first chemotherapy cycle by assessing the biomarker kinetics, which can be used to early identify patients who present resistance to platinum.

Despite the main limitation is the number of patients recruited during one year at a single cancer center, this public institution is considered one of the main centers of care for cancer patients nationwide. One the other hand, the main strengths are the sample was selected with strict control, and serum levels were collected before treatment and in each cycle, being one of the studies with the highest number of patients when studying HE4 thus conveying trustable results. The authors consider that a significant association with a limited sample size suggests a strong biological effect. The results will contribute with information that can be used for extension studies to get to a more comprehensive conclusion in an effective way.

Due to the nature and design of this study, it is not possible to conclude that HE4 biomarker has higher clinical utility in comparison with CA125, nor the benefits of their combination (as the used in the Risk of Ovarian Malignancy Algorithm). Literature on the subject is scarce, particularly in Hispanic populations like ours, and most of it is retrospective and done in the adjuvant context. However, it has been shown that preoperative levels 
of HE4 are a predictive factor of TR. Future studies must perform comparative, and combination analyzes with the purpose of exploring the potential usefulness of HE4.

\section{Conclusion}

Serum HE4 levels were independently associated with TR among patients with AEOC treated with NACT, also a reduction between baseline HE4 and first chemotherapy levels was also independently associated with the TR. These findings might be relevant for predicting a lack of response to treatment.

To the knowledge of the authors, this is the first report in Latin America on the kinetics of.

CA125 and HE4 as predictors of tomographic response in patients with advanced epithelial ovarian cancer treated with neoadjuvant platinum-based chemotherapy. Further study follow-up is needed to understand the impact of the biomarkers in terms of successful cytoreduction, in predicting platinum sensitivity, disease-free survival, risk to progress and overall survival.

\begin{abstract}
Abbreviations
AEOC: Advanced epithelial ovarian cancer; CA125: [Serological] blood cancer antigen 125; CMIA: Chemiluminescence Microparticle Immunoassay; CTCAE 5.0: Common Terminology Criteria for Adverse Events [version] 5.0; ECOG: Eastern Cooperative Oncology Group [performance status]; FIGO: International Federation of Gynecology and Obstetrics [stage classification]; HE4: [Serological] Human epididymal protein 4; NACT: Neoadjuvant chemotherapy; NCI-Mx: National Cancerology Institute, Mexico City; OC: Ovarian cancer; PET-CT: Positron Emission Tomography-Computerized Tomography; RECIST 1.1: Response evaluation criteria in solid tumors [version] 1.1; TR: Tomographic Response.
\end{abstract}

\section{Supplementary Information}

The online version contains supplementary material available at https://doi. org/10.1186/s13048-021-00845-6.

Additional file 1: Table S1. HE4 and CA125 serum levels quantified before and during the treatment with platinum-based neoadjuvant chemotherapy $(\mathrm{n}=53)$.

Additional file 2: Figure S1. HE4 and CA125 serum levels quantified before and during the treatment with platinum-based neoadjuvant chemotherapy $(n=53)$.

Additional file 3: Figure S2. Odds ratio and $95 \%$ confidence intervals for tomographic response versus characteristics of the patients $(n=53)$.

\section{Acknowledgements}

The authors would like to thank Clementina Castro for critical revision of this manuscript.

\section{Authors' contributions}

J.A.A.B.: Conceptualization, investigation, methodology, project administration, writing-original draft, review, and editing. J.C.J.L.: Data curation, formal analysis, software, visualization, review, and editing. A.V.C.: Data curation, contributor role, validation, review, and editing. D.F.C.L.: Conceptualization, methodology, supervision, validation, visualization. A.M.B.: Contributor role, resources, visualization. D.P.M.: Funding acquisition, investigation, methodology, contributor role and resources. G.S.D.: Contributor role, visualization, and writing-review. M.G.V.: Contributor role, visualization, and review. C.O.P: Contributor role, visualization, and review. A.H.C.: Contributor role, visualization, and review.
A.G.S.: Contributor role, visualization, and review. M.A.C.A.: Contributor role, visualization, and review. L.A.Q.: Contributor role, visualization, and review. D.G.P.O.: Formal analysis, methodology, contributor role, software, supervision, validation, visualization, review, and editing. All authors have reviewed and approved the final manuscript.

\section{Funding}

This work was supported by the National Institutes of Health (grants R21ES027087), and the Consejo Nacional de Ciencia y Tecnologia, CONACYT Mexico (FOSISS 2017-289503 and 2018-A3-S-48533, Prada).

\section{Availability of data and materials}

The datasets used and/or analyzed during the current study are available from the corresponding author on reasonable request.

\section{Declarations}

Ethics approval and consent to participate

The study was conducted following the guidelines of the General Law of Health in Research Matters for the Health-Mexico, the Declaration of Helsinki, and the ICH-Good Clinical Practices. The study was approved by the Institutional Ethics Committee and by the Institutional Review Board (015/037/ICI) of National Cancerology Institute. Before recruitment, each patient was informed about the protocol, asked for voluntary participation by verbal explanation, and signed the informed consent.

\section{Consent for publication}

Not applicable.

\section{Competing interests}

The authors declare that they have no competing interests.

\section{Author details}

${ }^{1}$ Oncology Center, Médica Sur, Mexico City, Mexico. ${ }^{2}$ Chemical Sciences Faculty, Universidad La Salle, Benjamín Franklin 45, 06140 Mexico City, Mexico. ${ }^{3}$ Science Faculty, Universidad Nacional Autónoma de México (UNAM), Mexico City, Mexico. ${ }^{4}$ Instituto Nacional de Cancerología, Colonia Seccion XVI, San Fernando 22, 14080 Tlalpan, Mexico City, Mexico. ${ }^{5}$ Centro Médico Nacional Siglo XXI, Mexico City, Mexico. ${ }^{6}$ Support and Promotion Program for Student Research, UNAM, Mexico City, Mexico. ${ }^{7}$ Department of Skin and Soft Tissue, Instituto Nacional de Cancerología, Mexico City, Mexico. ${ }^{8}$ Department of Molecular Imaging, Instituto Nacional de Cancerología, Mexico City, Mexico. ${ }^{9}$ Department of Environmental Health Sciences, Mailman School of Public Health, Columbia University, 722 W 168th St, New York, NY 10032, USA.

Received: 16 March 2021 Accepted: 2 July 2021

Published online: 19 July 2021

\section{References}

1. Gaona-Luviano P, Medina-Gaona LA, Magaña-Pérez K. Epidemiology of ovarian cancer. Chin Clin Oncol. 2020;9(4):47. https://doi.org/10.21037/ cco-20-34. Epub 2020 Jun 30. PMID: 32648448.

2. Coleridge SL, Bryant A, Lyons TJ, Goodall RJ, Kehoe S, Morrison J. Chemotherapy versus surgery for initial treatment in advanced ovarian epithelial cancer. Cochrane Database Syst Rev 2019;10:CD005343.

3. Tuninetti V, Di Napoli M, Ghisoni E, Maggiorotto F, Robella M, Scotto G, Giannone G, Turinetto M, Siatis D, Ponzone R, Vaira M, De Simone M, Scaffa C, Pignata S, Greggi S, Di Maio M, Valabrega G. Cytoreductive Surgery for Heavily Pre-Treated, Platinum-Resistant Epithelial Ovarian Carcinoma: A Two-Center Retrospective Experience. Cancers (Basel). 2020;12(8):2239. https://doi.org/10.3390/cancers12082239 PMID:3278519 3;PMCID:PMC7464658.

4. Elattar A, Bryant A, Winter-Roach BA, Hatem M, Naik R. Optimal primary surgical treatment for advanced epithelial ovarian cancer. Cochrane Database Syst Rev 2011;8:CD007565.

5. Nishio S, Ushijima K. Clinical significance of primary debulking surgery and neoadjuvant chemotherapy-interval debulking surgery in advanced 
ovarian cancer. Jpn J Clin Oncol. 2020;50(4):379-86. https://doi.org/10 1093/jjco/hyaa015.

6. Fagotti A, Ferrandina MG, Vizzielli G, Pasciuto T, Fanfani F, Gallotta V, Margariti PA, Chiantera V, Costantini B, Gueli Alletti S, Cosentino F, Scambia G. Randomized trial of primary debulking surgery versus neoadjuvant chemotherapy for advanced epithelial ovarian cancer (SCORPIONNCT01461850). Int J Gynecol Cancer. 2020;30(11):1657-64. https://doi. org/10.1136/ijgc-2020-001640.

7. Mueller JJ, Zhou QC, lasonos A, O'Cearbhaill RE, Alvi FA, El Haraki A, et al. Neoadjuvant chemotherapy and primary debulking surgery utilization for advanced-stage ovarian cancer at a comprehensive cancer center. Gynecol Oncol. 2016;140:436-42.

8. Machida H, Tokunaga H, Matsuo K, Matsumura N, Kobayashi Y, Tabata T, Kaneuchi M, Nagase S, Mikami M. Survival outcome and perioperative complication related to neoadjuvant chemotherapy with carboplatin and paclitaxel for advanced ovarian cancer: A systematic review and metaanalysis. Eur J Surg Oncol. 2020;46(5):868-75. https://doi.org/10.1016/j. ejso.2019.11.520.

9. Gill S, McGree M, Weaver A, Cliby WA, Langstraat CL. Optimizing the treatment of ovarian cancer: Neoadjuvant chemotherapy and interval debulking versus primary debulking surgery for epithelial ovarian cancers likely to have suboptimal resection. Gynecol Oncol. 2017;144(2):266-73.

10. Dochez V, Caillon H, Vaucel E, Dimet J, Winer N, Ducarme G. Biomarkers and algorithms for diagnosis of ovarian cancer: CA125, HE4, RMI and ROMA, a review. J Ovarian Res. 2019;12(1):28. https://doi.org/10.1186/ s13048-019-0503-7.

11. Bonifácio VDB. Ovarian Cancer Biomarkers: Moving Forward in Early Detection. Adv Exp Med Biol. 2020;1219:355-63. https://doi.org/10.1007/ 978-3-030-34025-4_18.

12. Jafarzadeh L, Khakpoor-Koosheh M, Mirzaei H, Mirzaei HR. Biomarkers for predicting the outcome of various cancer immunotherapies. Crit Rev Oncol Hematol. 2021;157: 103161. https://doi.org/10.1016/j.critrevonc. 2020.103161.

13. Scholler N, Urban N. CA125 in ovarian cancer. Biomark Med. 2007;1(4):513-23.

14. Morales FM, Santillán A. Antígeno sérico CA-125 en cáncer epitelial de Ovario. Cancerología. 2007;1:s21-4.

15. Colloca G, Venturino A, Governato I. CA125-related tumor cell kinetics variables after chemotherapy in advanced ovarian cancer: a systematic review. Clin Transl Oncol. 2016;18(8):813-24. https://doi.org/10.1007/ s12094-015-1441-5.

16. Van Altena AM, Kolwijck E, Spanjer MJ, Hendricks JC, Massuger LF, de Hullu JA. CA125 nadir concentration is an independent predictor of tumor recurrence in patients with ovarian cancer: a population-based study. Gynecol Oncol. 2010;119(2):265-9.

17. Riedinger JM, Wafflart J, Ricolleau G, Eche N, Larbre H, Basuyau JP, et al. CA125 half-life and CA125 nadir during induction chemotherapy are independent predictors of epithelial ovarian cancer outcome: results of a French multicentric study. Ann Oncol. 2006;17(8):1234-8.

18. Rodrìguez N, Rauh-Hain JA, Shoni M, Berkowitz RS, Muto MG, Feltmate C, et al. Changes in serum CA 125 can predict optimal cytoreduction to no gross residual disease in patients with advanced stage ovarian cancer treated with neoadjuvant chemotherapy. Gynecol Oncol. 2012;125(2):362-6.

19. Kang S, Seo SS, Park SY. Nadir CA125 level is an independent prognostic factor in advanced epithelial ovarian cancer. J Surg Oncol. 2009;100:244-7.

20. Prat A, Parera M, Peralta S, Perez-Benavente MA, Garcia A, Gil- Moreno A, et al. Nadir CA1 25 concentration in the normal range as an independent prognostic factor for optimally treated advanced epithelial ovarian cancer. Ann Oncol. 2008;19(2):327-31.

21. Markman M, Frederico M, Liu PY, Hannigan E, Alberts D. Significance of early changes in the serum CA 125 antigen level on overall survival in advanced ovarian cancer. Gynecol Oncol. 2006;103(1):195-8.

22. Makar AP, Kristensen GB, Bormer OP, Tropé CG. Serum CA125 level allows early identification of non-responders during induction chemotherapy. Gynecol Oncol. 1993:49(1):73-9.

23. Bingle $L$, Singleton $V$, Bingle CD. The putative ovarian tumour marker gene HE4 (WFDC2), is expressed in normal tissues and undergoes complex alternative splicing to yield multiple protein isoforms. Oncogene. 2002;21(17):2768-73.
24. Wang S, Wang C, Hu Y, Li X, Jin S, Liu O, Gou R, Zhuang Y, Guo Q, Nie X, Zhu L, Liu J, Lin B. ZNF703 promotes tumor progression in ovarian cancer by interacting with HE4 and epigenetically regulating PEA15. J Exp Clin Cancer Res. 2020;39(1):264.

25. Salminen L, Gidwani K, Grènman S, Carpén O, Hietanen S, Pettersson K, Huhtinen K, Hynninen J. HE4 in the evaluation of tumor load and prognostic stratification of high grade serous ovarian carcinoma. Acta Oncol. 2020;59(12):1461-8. https://doi.org/10.1080/0284186X.2020.1827157.

26. Galgano MT, Hampton GM, Frierson HF Jr. Comprehensive analysis of HE4 expression in normal and malignant human tissues. Mod Pathol. 2006;19(6):847-53.

27. Drapkin R, von Horsten HH, Lin Y, Mok SC, Crum CP, Welch WR, et al. Human epididymis protein 4 (HE4) is a secreted glycoprotein that is overexpressed by serous and endometrioid ovarian carcinomas. Cancer Res. 2005;65(6):2162-9.

28. Qiao L, Chen X, Xi X, Chen X, Zhang P, Dong H, Wu X, Chen X. Correlation analysis and clinical significance of CA125, HE4, DDI, and FDP in type Il epithelial ovarian cancer. Medicine (Baltimore). 2020;99(49): e23329. https://doi.org/10.1097/MD.0000000000023329.

29. He YP, Li LX, Tang JX, Yi L, Zhao Y, Zhang HW, et al. HE4 as a biomarker for diagnosis of lung cancer: A meta-analysis. Medicine (Baltimore) 2019;98;39:e17198.

30. Benati M, Montagnana M, Danese E, Paviati E, Giudici S, Ruzzenente O, et al. The clinical significance of DJ-1 and HE4 in patients with endometrial cancer. J Clin Lab Anal 2018;32;1:e22223.

31. Kumarasamy C, Madhav MR, Sabarimurugan S, Lakhotiya K, Pandey V, Priyadharshini T, et al. Diagnostic and prognostic role of HE4 expression in multiple carcinomas: A protocol for systematic review and meta-analysis. Medicine (Baltimore) 2019;98;28:e15336.

32. Gündüz UR, Gunaldi M, Isiksacan N, Gündüz S, Okuturlar Y, Kocoglu H. A new marker for breast cancer diagnosis, human epididymis protein 4: A preliminary study. Mol Clin Oncol. 2016;5(2):355-60.

33. Zou SL, Chang XH, Ye X, Cheng HY, Cheng YX, Tang ZJ, et al. Effect of human epididymis protein 4 gene silencing on the malignant phenotype in ovarian cancer. Chin Med J (Engl). 2011;124(19):3133-40.

34. Zhu YF, Gao GL, Tang SB, Zhang ZD, Huang QS. Effect of WFDC 2 silencing on the proliferation, motility and invasion of human serous ovarian cancer cells in vitro. Asian Pac J Trop Med. 2013;6(4):265-72.

35. Karlsen MA, Sandhu N, Høgdall C, Christensen IJ, Nedergaard L, Lundvall $L$, et al. Evaluation of HE4, CA125, risk of ovarian malignancy algorithm (ROMA) and risk of malignancy index (RMI) as diagnostic tools of epithelial ovarian cancer in patients with a pelvic mass. Gynecologic Oncology. 2012;127(2):379-83.

36. LiW, Wang D. The differential diagnostic value and clinical significance of serum HE4 in ovarian disease with elevated CA125. Arch Gynecol Obstet. 2020;301(5):1219-25. https://doi.org/10.1007/s00404-020-05527-0 Epub 2020 Apr 7 PMID: 32266526

37. Sun J, Cui XW, Li YS, Wang SY, Yin Q, Wang XN, Gu L. The value of $18 F-F D G$ PET/CT imaging combined with detection of CA125 and HE4 in the diagnosis of recurrence and metastasis of ovarian cancer. Eur Rev Med Pharmacol Sci. 2020;24(13):7276-7283. https://doi.org/10.26355/eurrev_ 202007_21882. PMID: 32706065 .

38. Hellstrom I, Heagerty PJ, Swisher EM, Liu P, Jaffar J, Agnew K, et al. Detection of the HE4 protein in urine as a biomarker for ovarian neoplasms. Cancer Lett. 2010;296(1):43-8.

39. Le T, Hopkins L, Faught W, Fung-Kee-Fung M. The lack of significance of Ca125 response in epithelial ovarian cancer patients treated with neoadjuvant chemotherapy and delayed primary surgical debulking. Gynecol Oncol. 2007;105(3):712-5.

40. Gadducci A, Fuso L, Cosio S, Landoni F, Maggino T, Perotto S, et al. Are surveillance procedures of clinical benefit for patients treated for ovarian cancer?: A retrospective Italian multicentric study. Int J Gynecol Cancer. 2009;19(3):367-74.

41. Almufti R, Wilbaux M, Oza A, Henin E, Freyer G, Tod M, et al. A critical review of the analytical approaches for circulating tumor biomarker kinetics during treatment. Ann Oncol. 2014;25(1):41-56.

42. Reid BM, Permuth JB, Sellers TA. Epidemiology of ovarian cancer: a review. Cancer Biol Med. 2017;14(1):9-32.

43. Muhabat, Q, Waheed, F, Waqarunissa, Jabeen N. Clinical presentation of ovarian tumors. Open J Obstetrics Gynecol 2016;6(4):205-9. 
44. Fujiwara K, Shintani D, Nishikawa T. Clear-cell carcinoma of the ovary. Ann Oncol. 2016;27(Suppl 1):i50-2. https://doi.org/10.1093/annonc/mdw086.

45. Babaier A, Ghatage P. Mucinous Cancer of the Ovary: Overview and Current Status. Diagnostics (Basel). 2020;10(1):52. https://doi.org/10.3390/ diagnostics10010052.

46. Lu R, Sun X, Xiao R, Zhou L, Gao X, Guo L. Human epididymis protein 4 (HE4) plays a key role in ovarian cancer cell adhesions and motility. Biochem Biophys Res Commun. 2012;419(2):274-80.

47. Dayyani F, Uhlig S, Colson B, Simon K, Rolny V, Morgenstern D, Schlumbrecht M. Diagnostic Performance of Risk of Ovarian Malignancy Algorithm Against CA125 and HE4 in Connection With Ovarian Cancer: A Metaanalysis. Int J Gynecol Cancer. 2016;26(9):1586-93. https://doi.org/10. 1097/IGC.0000000000000804.

48. Chacón E, Dasí J, Caballero C, Alcázar JL. Risk of Ovarian Malignancy Algorithm versus Risk Malignancy Index-I for Preoperative Assessment of Adnexal Masses: A Systematic Review and Meta-Analysis. Gynecol Obstet Invest. 2019;84(6):591-8. https://doi.org/10.1159/000501681 Epub 2019 Jul 16.

49. Chudecka-Głaz AM, Cymbaluk-Płoska AA, Menkiszak JI, SompolskaRzechuła AM, Tołoczko-Grabarek Al, Rzepka-Górska IA. Serum HE4, CA 125, YKL-10, bcl-2, cathepsin-L and prediction optimal debulking surgery, response to chemotherapy in ovarian cancer. J Ovarian Res 2014;7:62.

50. Scaletta G, Plotti F, Luvero D, Capriglione S, Montera R, Miranda A, Lopez S, Terranova C, De Cicco NC, Angioli R. The role of novel biomarker HE4 in the diagnosis, prognosis and follow-up of ovarian cancer: a systematic review. Expert Rev Anticancer Ther. 2017;17(9):827-39. https://doi.org/10. 1080/14737140.2017.1360138.

51. Capriglione S, Luvero D, Plotti F, Terranova C, Montera R, Scaletta G, Schirò T, Rossini G, Benedetti Panici P, Angioli R. Ovarian cancer recurrence and early detection: may HE4 play a key role in this open challenge? A systematic review of literature. Med Oncol. 2017;34(9):164. https://doi. org/10.1007/s12032-017-1026-y.

52. Vallius T, Hynninen J, Auranen A, Carpén O, Matomäki J, Oksa S, et al. Serum HE4 and CA125 as predictors of response and outcome during neoadjuvant chemotherapy of advanced high-grade serous ovarian cancer. Tumour Biol. 2014;35(12):12389-95.

53. Chudecka-Głaz, A., Cymbaluk-Płoska, A., Wężowska, M., \& Menkiszak, J. Could HE4 level measurements during first-line chemotherapy predict response to treatment among ovarian cancer patients?. PloS One 2018;13:3:e0194270.

\section{Publisher's Note}

Springer Nature remains neutral with regard to jurisdictional claims in published maps and institutional affiliations.
Ready to submit your research? Choose BMC and benefit from:

- fast, convenient online submission

- thorough peer review by experienced researchers in your field

- rapid publication on acceptance

- support for research data, including large and complex data types

- gold Open Access which fosters wider collaboration and increased citations

- maximum visibility for your research: over $100 \mathrm{M}$ website views per year

At BMC, research is always in progress.

Learn more biomedcentral.com/submissions 